\title{
Direito fundamental ao meio ambiente do trabalho digno: medidas de desinvisibilização do trabalhador
}

\author{
Fundamental right to the worthy work environment: \\ paths for the worker disinvisibilization
}

\author{
Vitor da Costa Honorato de Siqueira ${ }^{1}$ \\ Gilsilene Passon Picoretti Francischetto ${ }^{2}$
}

\begin{abstract}
1 Bacharel em Direito pela Faculdade de Direito de Vitória - FDV. Mestrando em Direitos e Garantias Fundamentais - FDV (CAPES 5). Membro do Grupo de Pesquisa "Invisibilidade Social e Energias Emancipatórias em Direitos Humanos". Advogado. E-mail: vitorchsiqueira@gmail.com

2 Mestre em Instituições Jurídico-Políticas pela Universidade Federal de Santa Catarina. Doutora em Direito e Economia pela Universidade Gama Filho. Pós-doutora em Ciências Sociais pela Universidade de Coimbra. Coordenadora do grupo de pesquisa "Invisibilidade Social e energias emancipatórias em Direitos Humanos". E-mail: gilsilenepasson@uol.com.br
\end{abstract}

RESUMO: O direito ao meio ambiente equilibrado é tutelado pela Constituição da República Federativa do Brasil, de 1988 e reverbera em diversas áreas do Direito, dentre elas o Direito do Trabalho. Muito embora tutelado, esse direito é constantemente violado quando se permite a sujeição do trabalhador à riscos para sua segurança e integridade física e mental. Em tempos de mudanças nas relações do trabalho e emprego engendradas pela chamada quarta revolução industrial, a proteção da integridade física-mental dos trabalhadores deve prevalecer, fortalecendo a fiscalização do cumprimento das normas, regras e princípios que permeiam o meio ambiente do trabalho.

Palavras-chave: Meio ambiente do trabalho. Direito fundamental. Invisibilidade social.

ABSTRACT: The right to a balanced environment is protected by the Constitution of the Federative Republic of Brazil of 1988 and reverberates in several areas of law, including Labor Law. Although protected, this right is constantly violated by allowing workers to be subjected to risks to their safety and physical and mental integrity. In times of changes in labor and employment relations engendered by the so-called fourth industrial revolution, the protection of workers' physical and mental integrity must prevail, strengthening the enforcement of the norms, rules and principles that permeate the work environment.

Keywords: Work environment. Fundamental right. Social invisibility.

Sumário: Introdução - 1 Meio Ambiente do Trabalho e sua Previsão Jurídica Constitucional - 2 Invisibilidade Social do Trabalhador Brasileiro e o Direito Fundamental ao Trabalho Digno - 3 Medidas Legais Relativas à Tutela do Meio Ambiente do Trabalho Digno e Promoção de Visibilidade Social dos Trabalhadores Brasileiros; 3.1 Ação Civil Pública; 3.2 Inquérito Civil; 3.3 Termo de Ajustamento de Conduta; 3.4 Realização de Audiências Públicas; 3.5 Inspeção do Trabalho vinculada ao Ministério do Trabalho; 3.6 Participação dos Sindicatos - Considerações Finais - Referências

\section{INTRODUÇÃO}

A ascensão do direito do trabalho pós revolução industrial do século XVIII frente a crise do Estado Liberal e o consequente reconhecimento de direitos dos trabalhadores engendrou maior proteção por parte do ordenamento jurídico e por parte dos aplicadores do direito aos que exerciam ofício para subsistência, sendo estes reconhecidamente vulneráveis. A proteção mencionada é fruto do surgimento do Estado Social que, diante da fragilidade do modelo de Estado que vigorava, fundamentalmente liberalista, passou a intervir 
na ordem econômica e social com o fito de reestabelecer o intervencionismo estatal, retirando-o da inércia pré-existente.

Sendo assim, o Direito do Trabalho nada mais é que a resposta estatal ao clamor público por maior intervenção na atividade econômica dos particulares, de modo a preservar aquele que notoriamente encontra-se em desvantagem em razão de sua hipossuficiência. Nesse sentido, ao se olhar para o ordenamento jurídico brasileiro, verifica-se a existência de normas que estão presentes não só na CRFB, de 1988, mas em toda a extensão infraconstitucional que abordam o direito do trabalho em uma perspectiva de proteção da integridade (física e psicológica, por exemplo) do trabalhador.

No que tange à tutela destes direitos, ressalta-se a existência do direito fundamental ao meio ambiente saudável e equilibrado que, muito embora previsto constitucionalmente e comumente associado a questões ecológicas, está bem presente no contexto trabalhista quando se refere ao meio ambiente do trabalho.

Com o reconhecimento da aplicabilidade do direito fundamental ao meio ambiente pelo legislador e pelos teóricos na esfera laborativa, oportuniza-se a proteção da classe social dos trabalhadores que periodicamente sofrem com a inobservância de preceitos legais e têm seus direitos violados por seus empregadores. Isto porque, por se tratar de parte hipossuficiente, dependente da contraprestação percebida mensalmente pelo trabalho empenhado, constantemente se submete a situações de risco que colocam sua segurança e saúde à mercê de violações.

Em função do reconhecimento do direito fundamental ao meio ambiente e sua aplicação na esfera juslaborativa, percebe-se que o trabalhador não se submete e tampouco se submeterá a qualquer trabalho, devendo ser um trabalho digno e devidamente seguro ambientalmente. Caso contrário, se submeter ao labor irregular seria uma punição, o que obviamente não traduz as lutas perseguidas pelos trabalhadores e toda a bagagem histórico-jurídica do Direito do Trabalho.

Cumpre informar que, enfrentando certa mudança paradigmática fomentada pela existência do que muitos chamam de uma quarta revolução industrial, paradigma este sinaliza a necessidade de adaptação do contrato do trabalho em detrimento das mudanças relacionadas ao modo de produção e organização econômica da forma que se conhece ${ }^{1}$. No entanto, a proteção da integridade física e mental do trabalhador deve permanecer e prevalecer.

Nesse sentido, somente por meio do reconhecimento do direito ao meio ambiente do trabalho, assegurado constitucionalmente, é que surgem medidas capazes de monitorar a observância da legislação, fiscalizar seu cumprimento no âmbito laborativo e punir eventuais descumprimentos para que, então, tais violações não sejam eventualidades rotineiras.

Por este motivo, questiona-se: quais são estas medidas capazes de promover maior visibilidade dos trabalhadores que tem seu direito ao meio ambiente do trabalho digno violado? O presente artigo, portanto, busca responder ao problema apresentado por intermédio do método dedutivo e de três capítulos. Em um primeiro momento, buscará exprimir o que seria o meio ambiente do trabalho, bem como apontar as normas brasileiras que o tutelam bem como a ideia de risco que permeia o ambiente laborativo.

Em um segundo momento, objetivará traduzir o conceito do trabalho digno, ressaltando a diferença entre trabalho degradante e trabalho digno abordando o conceito de invisibilidade social, fortemente ligada à classe dos trabalhadores. Ao final, apontará as medidas legais e administrativas cabíveis para a tutela do

\footnotetext{
${ }^{1}$ Nelson Mannrich, no 58ํㅡㄹ Congresso de Direito do Trabalho organizado pela LTr, realizado em São Paulo em 2018, sobre os impactos da revolução tecnológica no direito do trabalho e os novos profetas ressaltou que o contrato de trabalho deverá se adaptar a nova realidade desencadeada pela quarta revolução industrial.
} 
meio ambiente do trabalho digno e promoção da proteção do trabalhador.

\section{MEIO AMBIENTE DO TRABALHO E SUA PREVISÃO JURÍDICA CONSTITUCIONAL}

Em que se pese o objetivo deste capítulo de analisar o meio ambiente do trabalho, imperioso ressaltar que, para sua melhor compreensão, é necessário reconhecer a coexistência de diversas interpretações do termo meio ambiente. Aqui, adota-se conceito amplo que, segundo Rocha (2013, p. 99) “[...] inclua não somente os elementos naturais (água, flora, fauna, ar, ecossistemas, biosfera, recursos genéticos etc.), mas também os componentes ambientais humanos, em outras palavras, o ambiente construído pela ação antrópica".

Compreende-se como meio ambiente, portanto, não apenas conceito estritamente ecológico ligado a biodiversidade. No conceito adotado para o desenvolvimento linear deste artigo compreende-se como meio ambiente, o conjunto de elementos e fatores instituídos pela ação do homem por meio de sua ação inventiva e que compõe determinado locus, sendo estes elementos físicos ou não.

Da mesma forma que se apresenta o termo meio ambiente, com toda a sua generalidade e amplitude, o meio ambiente do trabalho não se limita ao espaço da empresa, como diriam aqueles que defendem interpretação restritiva do termo, definindo-se como o conjunto de todos os elementos, interrelações e condições que estão ligados ao trabalhador e afetam sua saúde física e mental, comportamento e valores reunidos no local do trabalho (ROCHA, 2013).

Muito embora exista a amplitude do termo meio ambiente do trabalho, o que pode ocasionar certa indeterminação conceitual, tal fator não impediu sua previsão normativa e constante atenção por parte do legislador, desde constitucional ao infraconstitucional, com o estabelecimento de regras e princípios que tutelam o meio ambiente do trabalho direta e indiretamente.

No que concerne à previsão jurídica e tutela de direitos que estão circunscritos no direito ao meio ambiente lato sensu, cumpre ressaltar o pioneirismo da CRFB, de 1988, acertadamente classificada por Silva como uma Constituição ambientalista (2006, p. 46) e por muitos apelidada de Constituição Verde, quando trata do direito ao meio ambiente de forma expressa no texto constitucional, refletindo forte tendência internacional fomentada pelo reconhecimento da terceira geração ${ }^{2}$ de Direitos Humanos Fundamentais, notadamente vinculada ao direito do consumidor, desenvolvimento social e principalmente à direitos ambientais.

Muitos são os dispositivos normativos presentes na CRFB, de 1988 que abordam ou tangenciam a temática relacionada ao meio ambiente em sentido amplo. Sob esse ponto, ressalte-se o Art. 225 deste mesmo diploma, que assegura a todos o direito ao meio ambiente ecologicamente equilibrado e atribuindo seu caráter difuso ao torná-lo bem de uso comum do povo. A respeito do assunto, Padilha pontua que

Parece-nos claro que quando a Constituição Federal, em seu art. 225, fala em meio ambiente ecologicamente equilibrado, está mencionando todos os aspectos do meio ambiente. E, ao dispor, ainda, que o homem para encontrar uma sadia qualidade de vida necessita viver nesse ambiente ecologicamente equilibrado, tornou obrigatória também a proteção do ambiente no qual o homem, normalmente, passa a maior parte de sua vida produtiva, qual seja, o do trabalho (2002, p. 32).

2 Bobbio (2004, p. 25) menciona a existência de 3 (três) gerações de direitos, dividindo-as cronologicamente, como em fases, sendo a primeira geração relacionada aos direitos de liberdade, a segunda geração, objeto de estudo deste trabalho, referente a direitos sociais e a terceira geração de direitos, vinculada aos direitos ambientais. 
Nessa esteira, ao se verificar a presença de dispositivos constitucionais que abordam o meio ambiente do trabalho em caráter específico, ressalta-se a previsão contida no Art. 200 da CRFB, de 1988, atribuindo ao Sistema Único de Saúde (SUS) a competência de zelar pela proteção do meio ambiente, inclusive o meio ambiente do trabalho.

Nesta mesma Constituição, também, cuida do meio ambiente do trabalho o inciso $\mathrm{V}$ do $\int 1^{\circ}$ do art. 225 ao conferir ao Poder Público o dever de "controlar a produção, a comercialização e o emprego de técnicas, métodos e substâncias que comportem risco para a vida, a qualidade de vida e o meio ambiente" (BRASIL, CRFB $/ 1988$, art. 225, inciso $\mathrm{V}, \int 1^{\circ}$ ) o que desencadeia a proteção do trabalhador e a observâncias das condições de trabalho experimentadas por este, restando evidente o reconhecimento do direito ao meio ambiente do trabalho equilibrado.

Muito embora pareça clara esta constatação, a opção feita pelo legislador constitucional pela expressão, meio ambiente do trabalho, evidenciado no art. 225, $\int 1^{\circ}$, inciso $\mathrm{V}$, traduz o objetivo de proteção do meio ambiente do trabalho de forma universal, não se restringindo apenas às relações de emprego. É possível ainda reconhecer a tutela do meio ambiente do trabalho por meio do princípio da dignidade da pessoa humana, prenunciado no art. $1^{\circ}$, inciso III da CRFB/88, sendo este um dos fundamentos da República.

Tal reconhecimento se dá primordialmente em função do disposto no art. 170 da CRFB, de 1988, que atribui à ordem econômica a função de assegurar uma vida digna com a observância de alguns princípios, dentre eles a defesa do meio ambiente, previsto no inciso VI do mesmo dispositivo e o pleno emprego, previsto no inciso VIII, idem. Assim, a dignidade humana é "um princípio de caráter absoluto, constitutivo da base ética norteadora de toda atividade econômica" (PADILHA, 2002, p. 43) e, consequentemente, das relações de trabalho.

Nota-se por meio da inteligência do art. 170 da CRFB, de 1988, portanto, a imprescindibilidade do labor para o sustento de uma vida digna e, por conseguinte, a necessidade de uma vida digna para manutenção da ordem econômica. Por este motivo, não é possível analisar o meio ambiente do trabalho dissociado do contexto de interrelações entre atividade econômica-trabalho-meio ambiente (PADILHA, 2002, p. 44), tampouco analisar o direito ao meio ambiente do trabalho dissociado ao princípio da dignidade da pessoa humana.

No entanto, mesmo sendo latente o reconhecimento do direito ao meio ambiente do trabalho, equilibrado e digno, o que se vê é o descaso para com este bem jurídico tutelado pela CRFB, de 1988. Tal afirmação é confirmada com os riscos com os quais os trabalhadores brasileiros lidam diariamente em suas atividades, risco este que será melhor abordado na seção subsequente, abordando a invisibilidade social enfrentada por este grupo, bem como o direito fundamental ao trabalho digno, intimamente ligado ao meio ambiente do trabalho.

\subsection{A IDEIA DE RISCO INSERIDA NO MEIO AMBIENTE LABORATIVO}

Naquilo que Beck (2010, p. 24) denomina de "modernidade tardia", a produção social de riqueza é acompanhada pela produção social de riscos. Neste sentido, os problemas advindos da produção, definição e distribuição de riscos produzidos pelo desenvolvimento tecnológico, no contexto da modernidade tardia, se sobrepõem aos problemas distributivos ligados à sociedade da escassez, extraindo-se a ideia de que os perigos instaurados atualmente estão ligados aos avanços tecnológicos e não ao modelo industrial tradicional que se conhece, fundamentalmente fabril.

A sociedade de risco, segundo Rocha (2013, p. 106), “enfrenta, como questão fundamental, a tarefa 
de evitar, minimizar e canalizar os perigos produzidos no processo avançado de modernização" de modo a priorizar o avanço econômico, sem que haja qualquer tipo de interferência neste processo. Em meio ao panorama social fomentado pela sociedade de risco, o que se vê é que

A história da distribuição de riscos mostra que estes se atêm, assim como as riquezas, ao esquema de classe - mas de modo inverso: as riquezas acumulam-se em cima, os riscos em baixo. Assim, os riscos parecem reforçar, e não revogar, a sociedade de classes. [...] Em face disto, os ricos (em termos de renda, poder, educação) podem comprar segurança e liberdade em relação ao risco (BECK, 2010, p. 41).

Frente a este cenário de priorização econômica, é de se esperar a distribuição de riscos de modo específico para cada classe ou camada social, de modo que a atribuição dos riscos conforme o poderio econômico é fator que reafirma a desigualdade social. O meio ambiente do trabalho, tutelado pela CRFB, de 1988, é o conjunto das mais diversas características que afetam o ser humano no desempenhar de suas atividades no trabalho, sendo um "locus dinâmico" (ROCHA, 2013, p. 99). Nesse sentido, muitos são os estudos estatísticos que buscam verificar os riscos enfrentados pelo trabalhador, sejam eles físicos ou psicológicos.

No Brasil, descuido, falta de equipamentos de segurança e até mesmo a exaustão provocam 700 mil acidentes de trabalho por ano, segundo dados da Previdência Social e do Ministério do Trabalho. Deste modo, os danos ocasionados pelos acidentes de trabalho reverberam na econômica, causando, desde o ano de 2012, impacto de R $\$ 22$ bilhões (MINAS GERAIS, 2018).

Os dados descritos anunciam a existência de riscos no meio ambiente do trabalho em grau alarmante. Para Rocha, "não é sem sentido que a ideia de risco se associa à possibilidade de exposição a um evento danoso ou a uma série de circunstâncias e situações que podem colocar em perigo a saúde e a vida dos trabalhadores" (2013, p. 104).

No contexto do trabalho, os riscos de sobrecarga, irradiação e contaminação em diferentes áreas da indústria são distribuídos de forma desigual levando em conta a profissão exercida (BECK, 2010, p. 41). Por este motivo, a ideia de risco está comumente associada ao contexto laborativo, na medida em que diversos trabalhadores são submetidos em maior ou menor grau aos riscos à sua integridade física e mental, a depender do tipo de atividade exercida por este.

Por certo, a hipossuficiência do trabalhador e sua vulnerabilidade, sobretudo econômica, leva a crer que "com a ameaça da redução da renda, uma maior tolerância ao risco pode ser gerada" (BECK, 2010, 42). Nesse sentido, somente o reconhecimento global do meio ambiente do trabalho e a compreensão de seus elementos é capaz de prevenir e eliminar estes riscos ligados ao labor humano (ROCHA, 2013).

Contudo, parece que os esforços para o reconhecimento dos elementos do meio ambiente do trabalho, como melhor forma de assimilar a noção de riscos, a fim de eliminá-los (e não os gerir como é feito), são poucos comparado à grande quantidade de acidentes de trabalho registrados. Acredita-se que isto se deve à invisibilidade social que permeia a categoria dos trabalhadores. As constantes violações de direitos experimentadas pela classe dos trabalhadores, sobretudo no que concerne aos direitos relacionados ao meio ambiente do trabalho, corroboram para tal entendimento, que será melhor detalhado na seção seguinte.

\section{INVISIBILIDADE SOCIAL DO TRABALHADOR BRASILEIRO E O DIREITO FUNDAMENTAL AO TRA- BALHO DIGNO}

As contínuas violações dos direitos trabalhistas relacionados ao meio ambiente do trabalho e a per- 
missão do exercício do labor que coloque em risco a segurança, saúde e integridade física e mental do trabalhador sinaliza a invisibilidade pública social que paira sobre os trabalhadores no Brasil. A invisibilidade pública, nas palavras de Costa (2004, p. 63), pode ser definida como "desaparecimento intersubjetivo do homem no meio de outros homens, é expressão pontiaguda de dois fenômenos psicossociais que assumem caráter crônico nas sociedades capitalistas: humilhação social e reificação".

A humilhação social é tida como um problema político, evidenciando o afastamento de determinada classe do âmbito público. Implica na "exclusão intersubjetiva de uma classe inteira de homens do âmbito público da iniciativa e da palavra, do âmbito da ação fundadora e do diálogo, do governo da cidade e do governo do trabalho" (COSTA, 2004, p. 63). No que tange a reificação, pode-se dizer que há uma valoração das coisas (sejam pessoas, relações ou objetos) por meio do fato econômico. Dessa forma, "tudo passa a contar, primariamente, como mercadoria" (COSTA, 2004, p. 63).

Dessa forma, a invisibilidade social a qual a classe dos trabalhadores está sujeita, somada a sua humilhação social e sua reificação, sobressalta a consideração de que o trabalhador é tido como objeto de uma engrenagem produtiva, implicando a ele seu valor meramente econômico, retirando sua voz e o afastando do círculo de relações sociais de modo a priorizar a atividade produtiva, desconsiderando sua subjetividade, sujeitando-o aos riscos do desenvolvimento do trabalho.

Não é objetivo deste artigo adentrar com grande profundidade na fissura social que permeia este assunto. No entanto, para melhor compreensão do que se discute, ressalta-se aquilo que parece ser uma antinomia constitucional entre a redução e a monetização do risco no trabalho (PADILHA, 2002) e (OLIVEIRA, 2011). A CRFB, de 1988 assevera em seu art. $7^{\circ}$ alguns direitos dos trabalhadores, dentre eles a redução dos riscos do trabalho (inciso XXII) e o adicional de remuneração em se tratando de exercício de atividades penosas, insalubres ou perigosas (inciso XXIII).

Muito embora o trabalho seja um Direito Fundamental constitucionalmente assegurado pelo art. 6, consagrando-o como direito social, sua previsão não exclui a imprescindibilidade da proteção da saúde e integridade do trabalhador, uma vez que o direito fundamental ao trabalho deve ser interpretado de acordo com as demais regras e princípios do ordenamento jurídico pátrio, dentre eles o princípio da dignidade da pessoa humana.

Este seria um exemplo claro da gestão dos riscos relacionados ao meio ambiente do trabalho (e não erradicação de riscos, como deveria existir), quando o legislador de um lado resguarda a integridade física e mental do trabalhador ao definir como direito a redução dos riscos do trabalho e do outro lado autoriza a indenização, por meio de remuneração, em caso de exercício de atividades insalubres e perigosas. Isto evidencia a reificação supramencionada quando o Estado afirma que não tolerará atividade que coloque em risco a vida, integridade e segurança do trabalhador, mas, ao mesmo tempo, garante adicionais para atividades insalubres e perigosas, valorando a saúde do trabalhador, tornando-a como mercadoria.

A gestão dos riscos e o consequente descomprometimento para com o meio ambiente do trabalho saudável e equilibrado desconsidera o direito fundamental ao trabalho digno. A dignidade da pessoa humana, como já mencionada é um dos fundamentos da República. Nesse sentido, imperioso ressaltar que: No desempenho das relações sociais, onde se destacam as trabalhistas, deve ser vedada a violação da dignidade, o que significa que o ser humano jamais poderá ser utilizado como objeto ou meio para a realização de querer alheio (DELGADO, 2015).

Por este motivo, somente por meio do reconhecimento da importância do trabalho prestado em condições dignas e que se revela o direito fundamental ao trabalho, que transcende a mera subserviência. 
Deixa de ser uma sujeição ao trabalho e passa a ser um direito ao trabalho (digno) (DELGADO, 2015). O trabalho digno evidentemente fundamenta-se na ideia de que todo e qualquer trabalho humano deve ser realizado não só em conformidade com o princípio da dignidade da pessoa humana, mas também, de acordo com as regulamentações que permeiam a relação trabalhista, devendo ser rechaçada toda e qualquer prática de usurpação de vantagens ou atribuição de estigmas em função do trabalho exercido.

Não por outro motivo, o meio ambiente do trabalho deve estar de acordo com as regras de saúde, higiene e segurança do trabalho. Caso contrário, estaria diante de severa agressão ao trabalhador e consequente violação de seu direito ao trabalho digno. Sendo assim, não há espaços para o trabalho em condições precárias no ordenamento jurídico brasileiro, tampouco a permissão de riscos no meio ambiente do trabalho que coloquem a saúde e integridade do trabalhador em cheque, "vez que não se enquadraria como direito fundamental ao trabalho digno e, sim, como artifício de crua mercantilização da força de trabalho humana" (DELGADO, 2015, p. 29).

Nessa esteira, se o trabalho é um direito assegurado constitucionalmente e deve ser regido pela dignidade da pessoa humana, o constante olhar para o meio ambiente do trabalho deve prevalecer, vez que este último é o conjunto de características que permeiam a atividade laborativa do trabalhador. Por esta razão não só o trabalho há de ser digno, como também o meio ambiente do trabalho deve ser digno, afim de retirar do trabalhador seu valor fundado no fato econômico e cuidar de seu valor humano, engendrando maior participação social deste grupo em decisões políticas que afetam diretamente as relações jurídicas as quais fazem parte.

Cumpre-nos, então, apontar quais medidas legais são cabíveis para a tutela do meio ambiente do trabalho, de modo a efetivar plenamente o direito fundamental ao trabalho digno apresentado e promover maior visibilidade dos trabalhadores subjugados que sofrem com a violação de seu direito ao meio ambiente do trabalho digno. É o que se propõe na seção que segue.

\section{MEDIDAS LEGAIS RELATIVAS À TUTELA DO MEIO AMBIENTE DO TRABALHO DIGNO E PROMO- ÇÃO DE VISIBILIDADE SOCIAL DOS TRABALHADORES BRASILEIROS}

Muitos são os instrumentos capazes de tutelar o meio ambiente do trabalho, de modo que meio ambiente do trabalho digno seja assegurado aos trabalhadores brasileiros. Estes instrumentos, em muitos casos, são capazes de reduzir a exposição do trabalhador aos riscos imanentes do meio ambiente laborativo. Nessa esteira, no que concerne à defesa do meio ambiente laborativo, o Ministério Público figura papel fundamental na sua proteção.

Dentre os instrumentos utilizados pelo parquet trabalhista na defesa deste direito é possível ressaltar a Ação Civil Pública, o Inquérito Civil, o Termo de Ajustamento de Conduta e a Audiência Pública. Além disso, outros atores sociais possuem grande protagonismo na defesa dos interesses da classe trabalhadora, como é o caso do sindicato que, assim como o Ministério Público do Trabalho, tem em seu escopo de atuação o combate as violações de direitos relacionado ao meio ambiente do trabalho.

\subsection{AÇÃO CIVIL PÚBLICA}

Criada pela Lei no 7.347/1985, alterada pelo Código de Defesa do Consumidor e de competência do Ministério Público e outros legitimados, como por exemplo sindicatos, esta Ação abrange direitos difusos e coletivos sendo, portanto, importante instrumento na proteção do meio ambiente do trabalho. Por meio 
desta, na seara trabalhista, busca-se o cumprimento de obrigações de fazer e não fazer relacionadas a medicina e segurança do trabalho, relacionadas ao meio ambiente do trabalho e, por meio de liminares, requerer a interdição das atividades de empresas em razão da não observância destas obrigações (MELO, 2001).

O estudo promovido por Cavalcante (2018) a respeito do uso deste instrumento da prevenção dos acidentes e doenças ocupacionais demonstra sua alta eficiência se comparado à tutela exercida por meio de ações individuais. Os valores fixados nestas ações tendem a ser expressivos e sinalizam repercussões sociais e econômicas, de modo a estimular os empregadores a melhorar as condições do meio ambiente do trabalho nas empresas.

Sendo assim, além de sua ampla utilização em outras áreas do Direito, como por exemplo, em demandas consumeristas ou ambientais ligadas a questões ecológicas, a Ação Civil Pública é amplamente aplicável em demandas que envolvam a tutela de direitos de natureza difusa ou coletiva, sendo, portanto, forte medida na tutela do direito ao meio ambiente do trabalho digno.

\subsection{INQUÉRITO CIVIL}

O Inquérito Civil, assim como a Ação Civil Pública, é relevante na tutela do meio ambiente do trabalho. Instituído pela Lei 7.347/1985 e reafirmado pela CRFB, de 1988, este instrumento presta a investigação administrativa, pelo Ministério Público, para coleta de elementos para propositura de Ação Civil Pública, não sendo pressuposto necessário para sua propositura. Da mesma maneira, é ferramenta capaz de subsidiar Termos de Ajustamento de Conduta e realização de Audiências Públicas.

Dessa forma, em conjunto com a Ação Civil Pública, o Inquérito Civil é ferramenta cognitiva importante para a proteção e tutela do direito ao meio ambiente do trabalho digno e consequente preservação da integridade física e psicológica do trabalhador.

\subsection{TERMO DE AJUSTAMENTO DE CONDUTA}

O Termo de Ajustamento de Conduta, por seu turno, também figura como instrumento na preservação da dignidade do trabalhador em seu meio ambiente laborativo. Regulado pelo art. $5^{\circ}$, $\int 6^{\circ}$ da Lei $7.347 / 1985$, tem natureza de título executivo extrajudicial e fomenta maior agilidade e efetividade da tutela de direitos difusos, coletivos e individuais homogêneos. Pode o Ministério Público do Trabalho, utilizandose deste instrumento, firmar compromisso de ajustamento de conduta durante Inquérito Civil onde o inquirido se compromete a dar, fazer ou deixar de fazer algo em detrimento da ordem jurídica imposta, estipulando multa em caso de descumprimento do pacto formulado (MELO, 2001).

Por este motivo, é possível concluir que o Termo de Ajustamento de Conduta é ferramenta eficaz na tutela do direito ao meio ambiente do trabalho digno na medida em que, de forma célere e por meio de método alternativo de resolução de conflitos, é possível obter um resultado satisfatório e consequente proteção do meio ambiente laborativo em função do pacto firmado entre o inquirido e o Ministério Público do Trabalho.

\subsection{REALIZAÇÃO DE AUDIÊNCIAS PÚBLICAS}

Ressalte-se, também, a realização de Audiências Públicas, pelo Ministério Público, para convocação do cidadão e de entidades civil com fito de juntos colaborarem com o Ministério Público na realização de 
suas atividades institucionais. A respeito do assunto, Melo (2001, p. 105) afirma que "Essas audiências, como temos verificado na prática, têm-se revelado instrumentos eficientes de resolução de problemas ligados aos interesses e direitos difusos, coletivos e individuais homogêneos"

Concluindo que a implementação de tais Audiências Públicas na prática institucional tem auxiliado nos assuntos relacionados ao "trabalho de crianças e adolescentes e o meio ambiente do trabalho, quando se esclarece as partes e ouvintes sobre determinadas irregularidades, indicando os caminhos legais a serem trilhados, mas também dizendo sobre as consequências pela manutenção de conduta irregular [...]” (MELO, 2001, p. 105). Esta seria importante medida não só de tutela de direitos, mas também de conscientização de empregados e empregadores para prevenção de eventuais ilicitudes que reflitam na violação do direito ao meio ambiente laborativo digno.

\subsection{INSPEÇÃO DO TRABALHO VINCULADA AO MINISTÉRIO DO TRABALHO}

Para além da atuação do Ministério Público do Trabalho e da utilização dos instrumentos supramencionados, o Ministério do Trabalho e Emprego também exerce papel importante na proteção do meio ambiente do trabalho por intermédio da Inspeção do Trabalho, prevista no art. 21, inciso XXIV da CRFB, de 1988, tendo como função primordial a verificação do cumprimento dos dispositivos legais, regulamentares e normativos no âmbito das relações de trabalho (OLIVEIRA, 2011).

Regulamentada com a emissão do Decreto no 4.552/2002, a atividade do Auditor Fiscal do Trabalho tem como escopo certas atribuições diretamente relacionadas à segurança e saúde do trabalho e consequentemente ao meio ambiente do trabalho, como por exemplo o dever de averiguar e analisar situações com risco potencial de gerar doenças ocupacionais e acidentes do trabalho, determinando as medidas preventivas necessárias, conforme preconiza o art. 18 deste mesmo Decreto (OLIVEIRA, 2011).

A Inspeção do Trabalho, portanto, mostra-se como importante instrumento administrativo na tutela do meio ambiente do trabalho, sobretudo atuando no campo de prevenção de violações de direitos ligados ao meio ambiente laborativo e conscientização de empregados e empregadores quanto a imprescindibilidade de conhecerem e cumprirem com o dever legal de preservação do direito ao meio ambiente equilibrado e digno.

\subsection{PARTICIPAÇÃO DOS SINDICATOS}

Para além das ferramentas supramencionadas, relacionadas a atores diretamente ligados ao poder público, que centralizam o protagonismo do Ministério Público do Trabalho e, no caso da Inspeção do Trabalho, do Ministério do Trabalho e Emprego, ressaltamos a ação importante dos sindicatos na proteção do meio ambiente do trabalho, que tem crescido com a recente tendência de valorização das negociações coletivas realizadas pelos atores sociais (OLIVEIRA, 2011).

Muito embora os sindicatos não exerçam o poder de polícia e não possuam a capacidade de aplicar sanções, como é feito pelo Ministério do Trabalho e Emprego, por exemplo, sempre terão a faculdade de provocar a fiscalização pelo Ministério do Trabalho, apresentando denúncias e sendo facultado a estes acompanhar as fiscalizações para indicar infrações, conforme disposição do art. 19, \ 4 ${ }^{\circ}$, da Lei no 8.213/1991 e no art. 339 do Decreto n. 3.048/1999 (OLIVEIRA, 2011, p. 463).

A participação dos sindicatos, assim como a utilização das demais medidas supramencionadas, é indispensável para o exercício da proteção do direito ao meio ambiente do trabalho digno na medida em 
que sua atuação não se restringe a questões econômicas salariais, sendo sua atuação marcada por protagonismo político ativo, sendo o exercício de sua função social, sobretudo no que concerne a busca do melhor interesse do grupo que representa, de fundamental importância para o trabalhador brasileiro.

\section{CONSIDERAÇÕES FINAIS}

Muito embora tutelado pela CRFB, de 1988, o meio ambiente do trabalho é comumente mitigado em razão dos riscos aos quais os trabalhadores brasileiros são submetidos em suas atividades laborativas. A subsistência de violações de direitos relacionada ao meio ambiente do trabalho está intimamente ligada à invisibilidade social que perpassa a história da classe dos trabalhadores no mundo, não sendo diferente do Brasil.

Ainda que previstos no ordenamento jurídico, muitos desses direitos são negligenciados em função do fato econômico atribuído ao ser humano, desconsiderando o princípio da dignidade humana. Os dados estatísticos de acidentes do trabalho demonstrados evidenciam tal afirmação. Nesse sentido, somente o reconhecimento do meio ambiente do trabalho digno oportunizará com maior força e vigor sua tutela no âmbito das relações trabalhistas. A dignidade da pessoa humana, princípio que norteia o paradigma constitucional no qual está inseridos, preconiza a consideração do valor humano do trabalhador, e não seu valor econômico.

Instrumentos jurídicos e medidas político-institucionais podem ser utilizados para proteção do meio ambiente do trabalho digno em caso de violações, como é o caso da Ação Civil Pública, Inquérito Civil, formulação de Termos de Ajustamento de Conduta, realização de Audiências Públicas, efetivação de Inspeções do Trabalho e a participação proativa dos sindicatos na fiscalização do meio ambiente laborativo em conjunto com o Ministério do Trabalho e Emprego e Ministério Público do Trabalho.

Cumpre, então, ao direito e aos seus aplicadores a tarefa de proteger, à luz do ordenamento jurídico e por meio das ferramentas por ele fornecidas, a parte hipossuficiente de uma relação historicamente desigual: a classe dos trabalhadores. Classe esta que sabe "o que é não ter, e ter que ter pra dar" (Esquinas, DJAVAN, 1984).

\section{REFERÊNCIAS}

BECK, Ulrich. Sociedade de risco: rumo a uma outra modernidade. Tradução de Sebastião Nascimento. São Paulo: Editora 34, 2010.

BOBBIO, N. A era dos Direitos. Rio de Janeiro: Elsevier, 2004 [1989].

BRASIL. Constituição da República Federativa do Brasil de 1988. Brasília/DF. Disponível em: <http://www.planalto.gov.br/ccivil_03/constituicao/constituicaocompilado.htm>. Acesso em: 27 mai. 2018.

Decreto N³.048, de 6 de Maio de 1999. Aprova o Regulamento da Previdência Social, e dá outras providências. Disponível em: <http://www.planalto.gov.br/ccivil_03/decreto/D3048. htm> Acesso em: 27 mai. 2018.

Decreto No 4.552, de 27 de Dezembro de 2002. Aprova o Regulamento da Inspeção do Trabalho. Disponível em: <http://www.planalto.gov.br/ccivil_03/decreto/2002/d4552.htm> Acesso em: 22 jun. 2018. 
. Lei № 8.213, de 24 de Julho de 1991. Dispõe sobre os Planos de Benefícios da Previdência Social e dá outras providências. Disponível em: <http://www.planalto.gov.br/ccivil_03/leis/ L8213cons.htm> Acesso em: 27 mai. 2018.

. Lei $N^{\circ}$ 7.347, de 24 de Julho de 1985. Disciplina a ação civil pública de responsabilidade por danos causados ao meio-ambiente, ao consumidor, a bens e direitos de valor artístico, estético, histórico, turístico e paisagístico (VETADO) e dá outras providências. Disponível em: <http://www.planalto.gov.br/ccivil_03/leis/L7347orig.htm> Acesso em: 14 out. 2018.

CAVALCANTE, Sandra Regina. O papel das Ações Civis Públicas na prevenção de acidentes e doenças ocupacionais: alta eficiência e baixo custo. In: ROCHA, Claudio Jannotti da... [et al.] Proteção à saúde e segurança no trabalho. São Paulo: LTr, 2018, p. 313 - 317.

COSTA, Fernando Braga da. Homens invisíveis: relatos de uma humilhação social. São Paulo: Globo, 2004.

DELGADO, Gabriela Neves. Direito fundamental ao trabalho digno. 2. ed., São Paulo: LTr, 2015.

DJAVAN. Esquinas. Disponível em: <https://www.letras.mus.br/djavan/45521/> Acesso em: 12 out. 2018.

MELO, Raimundo Simão de. Alguns instrumentos de defesa do meio ambiente do trabalho. In: Revista de Direito do Trabalho. Ano 27. n. 101. São Paulo: RT, 2001.

MINAS GERAIS. Brasil tem 700 mil acidentes de trabalho por ano. Disponível em: <https://www.em.com.br/app/noticia/economia/2017/06/05/internas_economia,874113/brasil-tem-700-mil-acidentes-de-trabalho-por-ano.shtml> Acesso em: 10 out. 2018.

OLIVEIRA, Sebastião Geraldo de. Proteção jurídica à saúde do trabalhador. 6. ed. São Paulo: LTr, 2011

PADILHA, Norma Sueli. Do meio ambiente do trabalho equilibrado. São Paulo: LTr, 2002.

ROCHA, Júlio Cesar de Sá da. Direito ambiental do trabalho: mudanças de paradigma da tutela jurídica à saúde do trabalhador. São Paulo: Atlas, 2013.

SILVA, José Afonso da. Direito ambiental constitucional. 4. ed. São Paulo: Malheiros, 2006. p. 46. 